\title{
Room Temperature Cannizzaro Reaction under Mild Conditions Facilitated by Magnesium Bromide Ethyl Etherate and Triethylamine
}

\author{
M. Saeed Abaee,* Roholah Sharifi, and Mohammad M. Mojtahedi
}

Organic Chemistry Laboratory, Chemistry \& Chemical Engineering Research Center of Iran, P.O.Box 14335-186, Tehran, Iran abaee@ccerci.ac.ir

\section{1a. General procedure for intermolecular Cannizzaro reaction of aromatic aldehydes}

$$
\text { Ar } \stackrel{\mathrm{O}}{\underset{\mathrm{TEA}, \mathrm{CH}_{2} \mathrm{Cl}_{2}, 2 \mathrm{~d}}{\mathrm{MgBr}_{2} \cdot \mathrm{OEt}_{2}}} \mathrm{Ar}_{\mathrm{Hr}}^{\mathrm{OH}}+\stackrel{\mathrm{O}}{\mathrm{OH}}
$$

A mixture of $\mathrm{MgBr}_{2} \cdot \mathrm{OEt}_{2}(1 \mathrm{mmol})$ and triethylamine $(4 \mathrm{mmol})$ in dichloromethane $(3 \mathrm{~mL})$ was stirred for 5 minutes at room temperature under inert atmosphere. To this mixture was added aldehyde $(2 \mathrm{mmol})$ and the mixture was continued to stir at room temperature for 2 days until complete consumption of the aldehyde was observed. Progress of the reaction was monitored by TLC and GC analyses. The mixture was diluted by dichloromethane, washed by water, and the organic phase was evaporated after being dried over $\mathrm{Na}_{2} \mathrm{SO}_{4}$. Analysis of the residue by ${ }^{1} \mathrm{H}$ NMR and GC or GC-MS showed the formation of the corresponding alcohol and carboxylic acid in equal amounts. The alcohol portion was separated either by distillation or by basic separation of the acid portion. The results are reflected in the table 1 .

Table 1

\begin{tabular}{|c|c|c|c|}
\hline entry & aldehyde & \%conversion (GC) & \%Alcohol (isolated) \\
\hline 1 & benzaldehyde & 98 & 90 \\
\hline 2 & $p$-methylbenzaldehyde & 97 & 91 \\
\hline 3 & $p$-methoxybenzaldehyde & 97 & 85 \\
\hline 4 & $p$-chlorobenzaldehyde & 95 & 88 \\
\hline 5 & furfural & 92 & 90 \\
\hline 6 & $p$-nitrobenzaldehyde & $97 *$ & 85 \\
\hline 7 & Pyridine-3-carbaldehyde & 92 & 82 \\
\hline
\end{tabular}

* Completed in $24 \mathrm{~h}$. 
1b. Intermolecular Cannizzaro reaction of benzaldehyde $(2 \mathrm{mmol})$ in the presence of other Lewis Acids (1 mmol) and TEA* $(4 \mathrm{mmol})$

Table 2

\begin{tabular}{|c|c|c|}
\hline entry & Lewis Acid & \%Alcohol (GC) \\
\hline 1 & $\mathrm{LiCl}$ & NR \\
\hline 2 & $\mathrm{LiBr}$ & 3 \\
\hline 3 & $\mathrm{AlCl}_{3}$ & 60 \\
\hline 4 & $\mathrm{AlBr}_{3}$ & 67 \\
\hline 5 & $\mathrm{ZnCl}_{2}$ & 8 \\
\hline 6 & $\mathrm{ZnBr}_{2}$ & 45 \\
\hline 7 & $\mathrm{TiCl}_{4}$ & 56 \\
\hline 8 & $\mathrm{SnCl}_{4}$ & 4 \\
\hline 9 & $\mathrm{MgCl}_{2}$ & 8 \\
\hline 10 & $\mathrm{LiClO}_{4}$ & 34 \\
\hline
\end{tabular}

*Reactions do not proceed without TEA. 
2. Conversion of $o$ - phtalaldehyde to $3 H$-isobenzofuran-1-one

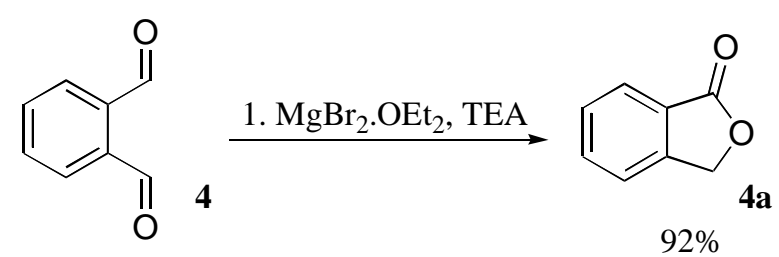

A mixture of $\mathrm{MgBr}_{2} \cdot \mathrm{OEt}_{2}(5 \mathrm{mmol})$ and triethylamine $(10 \mathrm{mmol})$ in dichloromethane $(10 \mathrm{~mL})$ was stirred for 5 minutes at room temperature under inert atmosphere. To this mixture was added $o$-phtalaldehyde $(5 \mathrm{mmol})$ and the mixture was continued to stir at room temperature for 2 days until complete consumption of the aldehyde. Progress of the reaction was monitored by TLC and GC analyses. The mixture was diluted by dichloromethane, washed by water, and the organic phase was evaporated after being dried over $\mathrm{Na}_{2} \mathrm{SO}_{4}$. Analysis of the residue by ${ }^{1} \mathrm{H}$ NMR and GC or GC-MS showed the formation of the desired lactone (620 mg, 92\%).

Attempt to conduct the reaction with catalytic amount of $\mathrm{MgBr}_{2} \cdot \mathrm{OEt}_{2}(0.1 \mathrm{eq})$ resulted in formation of only $15 \%$ product.

\section{Conversion of phenylglyoxal to $\alpha$-hydroxy-phenylacetic acid methyl ester}

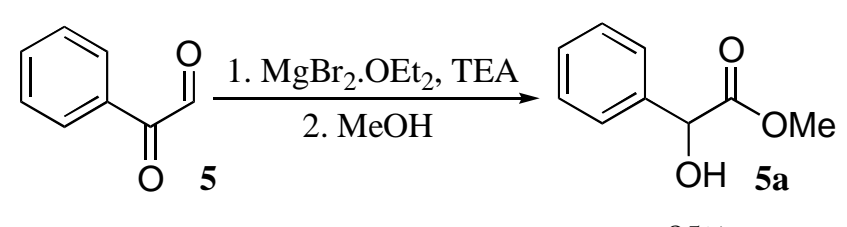

$85 \%$

A mixture of $\mathrm{MgBr}_{2} \cdot \mathrm{OEt}_{2}(5 \mathrm{mmol})$ and triethylamine $(10 \mathrm{mmol})$ in dichloromethane $(10 \mathrm{~mL})$ was stirred for 5 minutes at room temperature under inert atmosphere. To this mixture was added phenylglyoxal $(5 \mathrm{mmol})$ and the mixture was continued to stir at room temperature for 2 days until complete consumption of the aldehyde was observed. Progress of the reaction was monitored by TLC and GC analyses. The mixture was diluted by dichloromethane, washed by water, and the organic phase was evaporated after being dried over $\mathrm{Na}_{2} \mathrm{SO}_{4}$. To the solid residue was added excessive methanol and few drops of concentrated sulfuric acid and the mixture was stirred for 2 hours. The mixture was diluted by dichloromethane, washed by saturated sodium bicarbonate solution, and water and the organic phase was dried over $\mathrm{Na}_{2} \mathrm{SO}_{4}$. $\mathrm{An}$ amount of 710 $\mathrm{mg}(85 \%)$ of the desired product obtained after evaporation of the solvent. 


\section{Conversion of benzaldehyde to benzyl alcohol and $N, N$-diethylbenzamide}

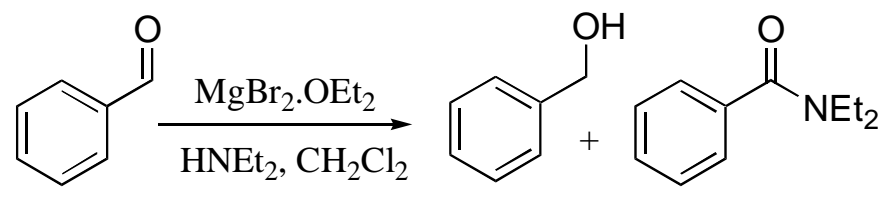

A mixture of $\mathrm{MgBr}_{2} \cdot \mathrm{OEt}_{2}(1 \mathrm{mmol})$ and diethylamine $(4 \mathrm{mmol})$ in dichloromethane $(3 \mathrm{~mL})$ was stirred for 5 minutes at room temperature under inert atmosphere. To this mixture was added benzaldehyde $(2 \mathrm{mmol})$ and the mixture was continued to stir at room temperature for 2 days until complete consumption of the aldehyde was observed. Progress of the reaction was monitored by TLC and GC analyses. The mixture was diluted by dichloromethane, washed by water, and the volatile portion was evaporated after being dried over $\mathrm{Na}_{2} \mathrm{SO}_{4}$. The alcohol (95 mg, $88 \%$ ) and amide (150 mg, 85\%) portions were separated by fractional distillation.

Attempt to conduct the reaction with catalytic amount of $\mathrm{MgBr}_{2} . \mathrm{OEt}_{2}(0.1 \mathrm{mmol})$ resulted in formation of only $16 \%$ product.

\section{Conversion of benzaldehyde to benzyl alcohol and methylbenzoate}

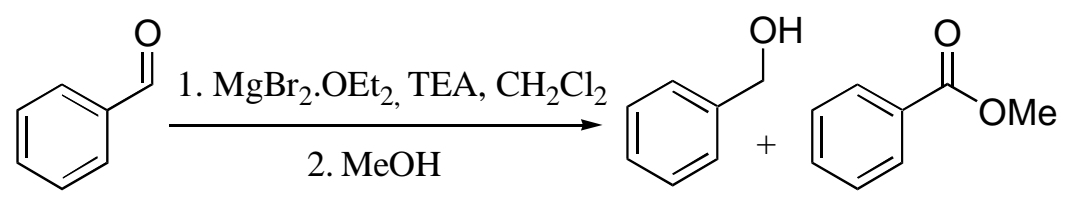

A mixture of $\mathrm{MgBr}_{2} . \mathrm{OEt}_{2}(1 \mathrm{mmol})$ and triethylamine $(4 \mathrm{mmol})$ in dichloromethane $(3 \mathrm{~mL})$ was stirred for 5 minutes at room temperature under inert atmosphere. To this mixture was added benzaldehyde $(2 \mathrm{mmol})$ and the mixture was continued to stir at room temperature for 2 days until complete consumption of the aldehyde was observed. Progress of the reaction was monitored by TLC and GC analyses. The mixture was diluted by dry methanol $(5 \mathrm{~mL})$ and mixing continued until complete formation of methyl benzoate. The volatile portion was evaporated. The alcohol (98 mg, 91\%) and ester (122 mg, 90\%) portions were separated by fractional column chromatography. 


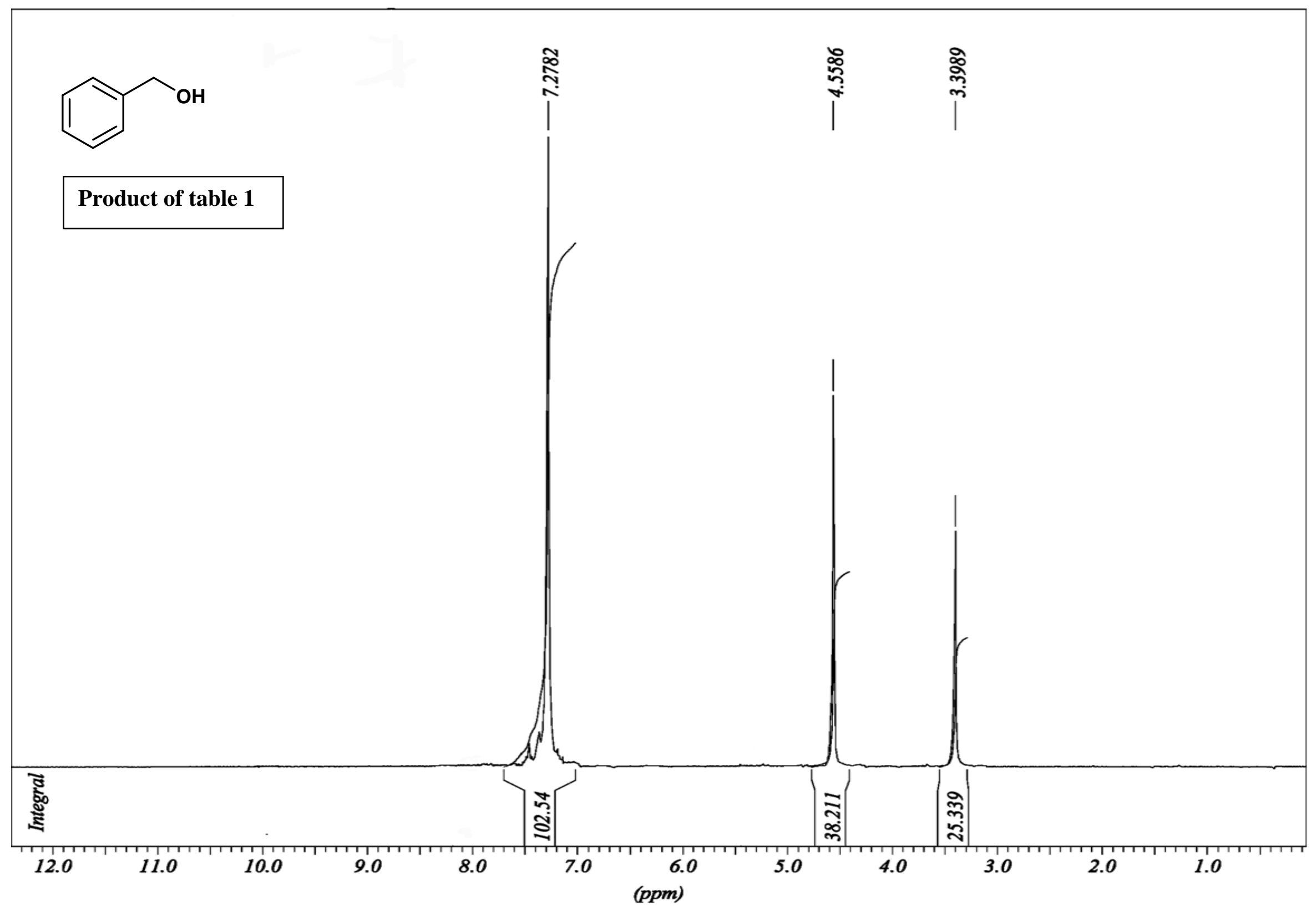




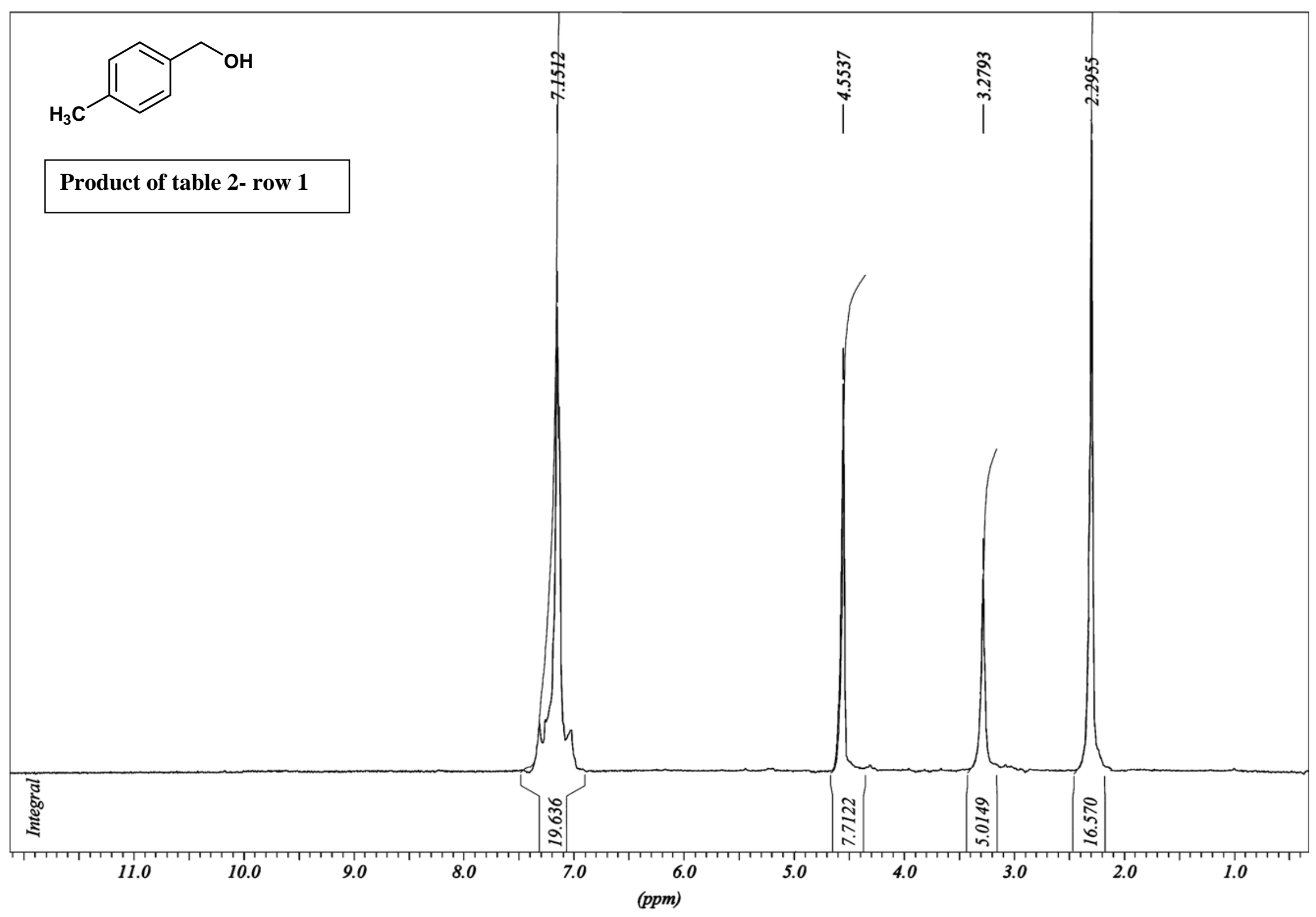




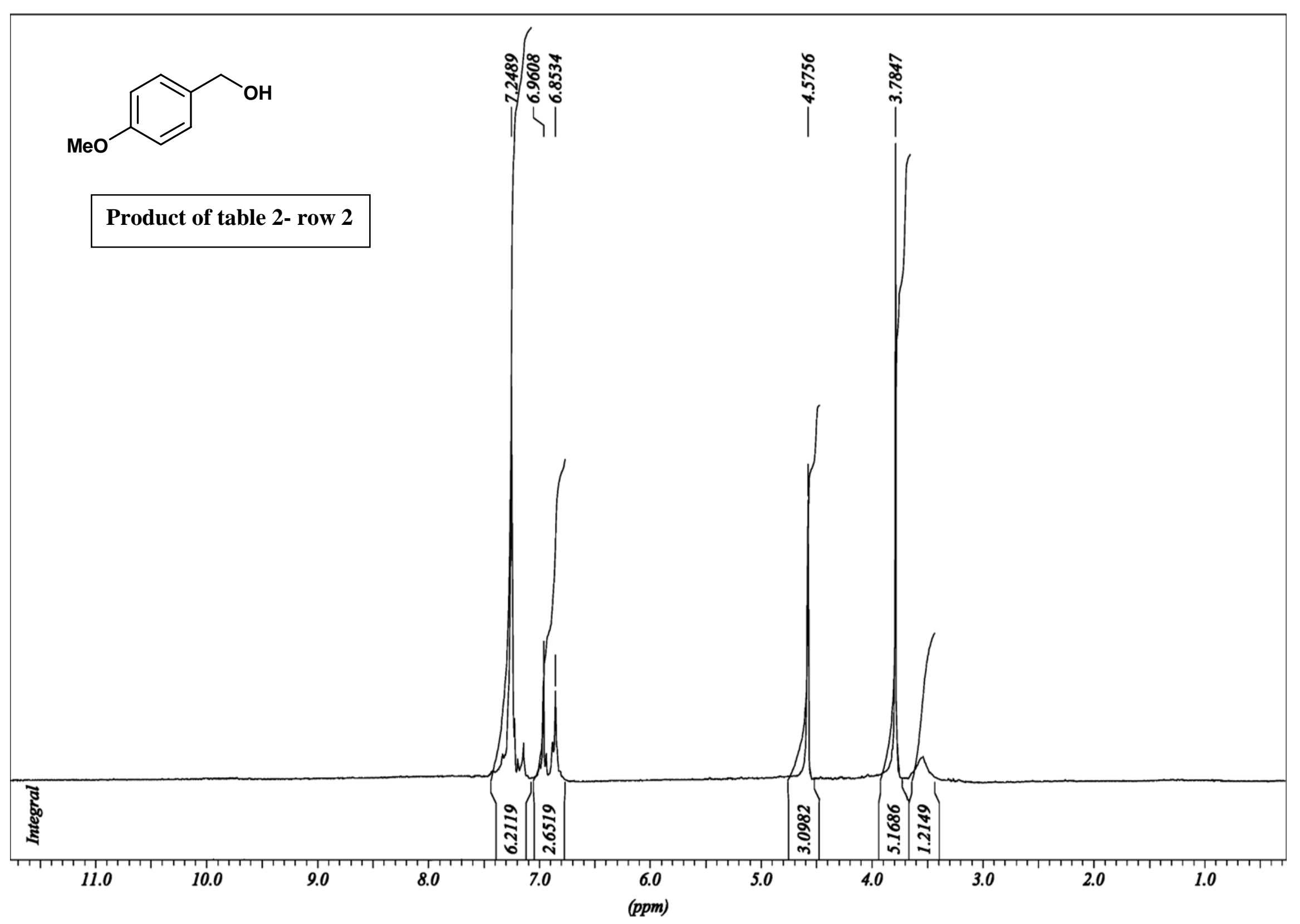




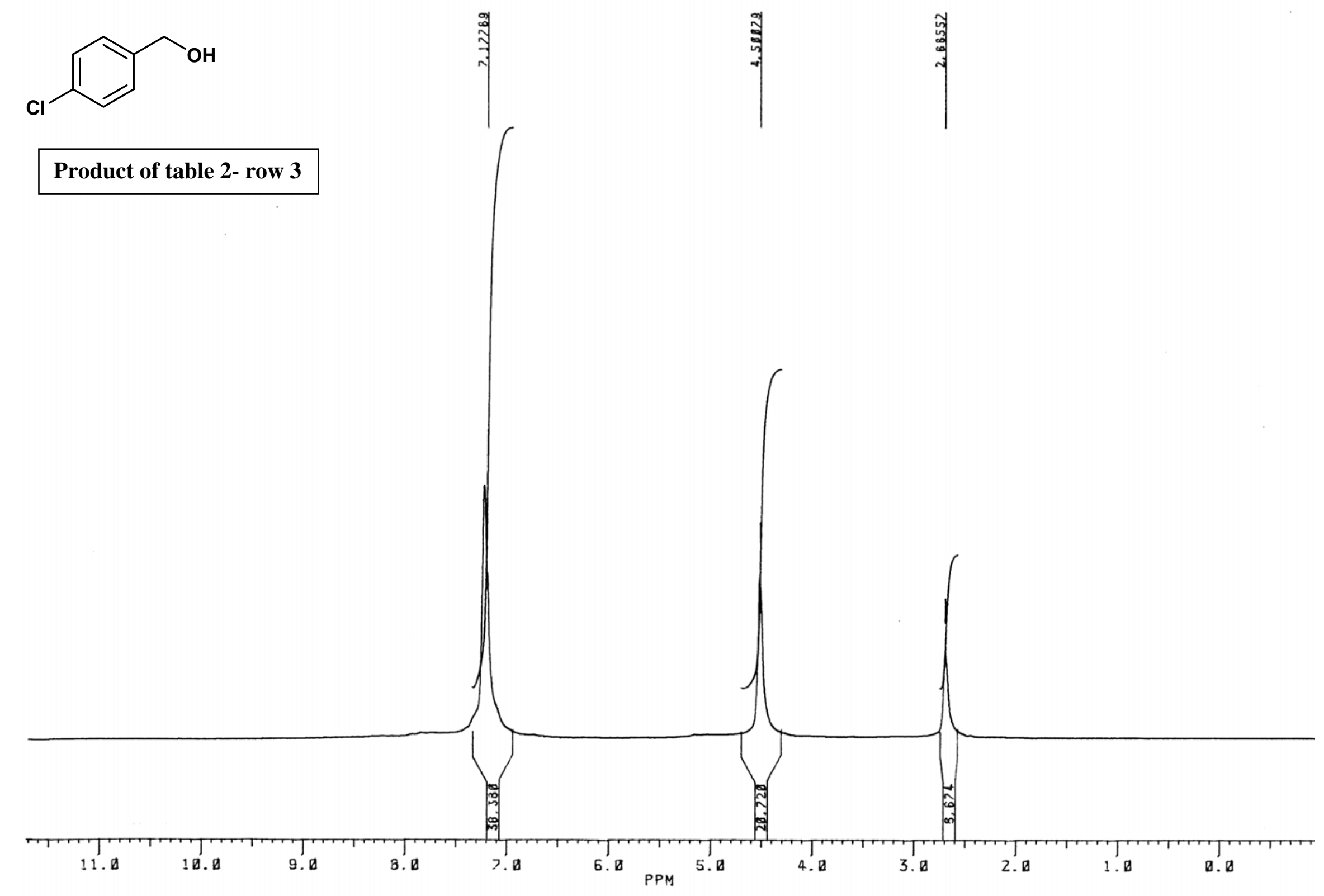




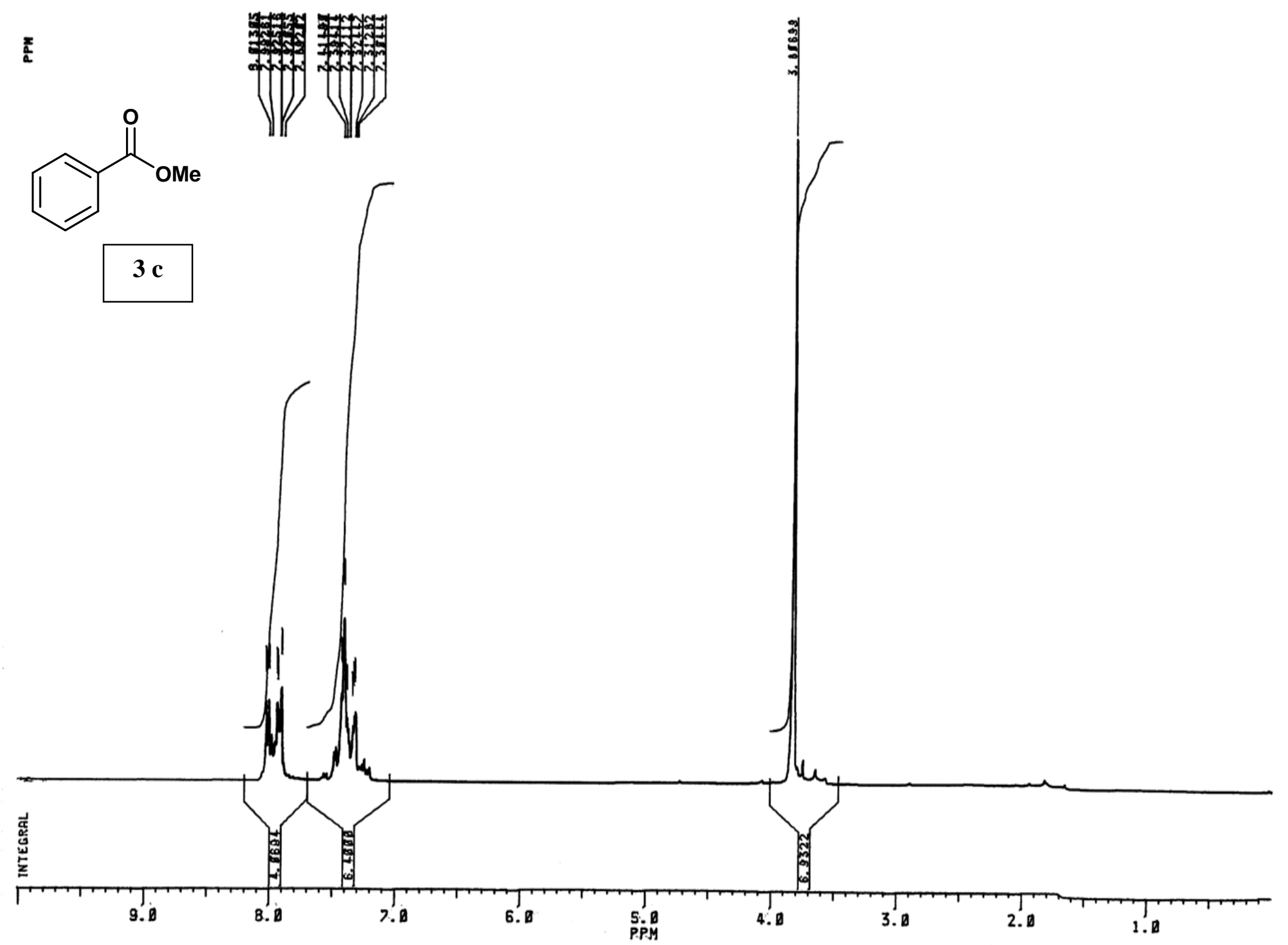




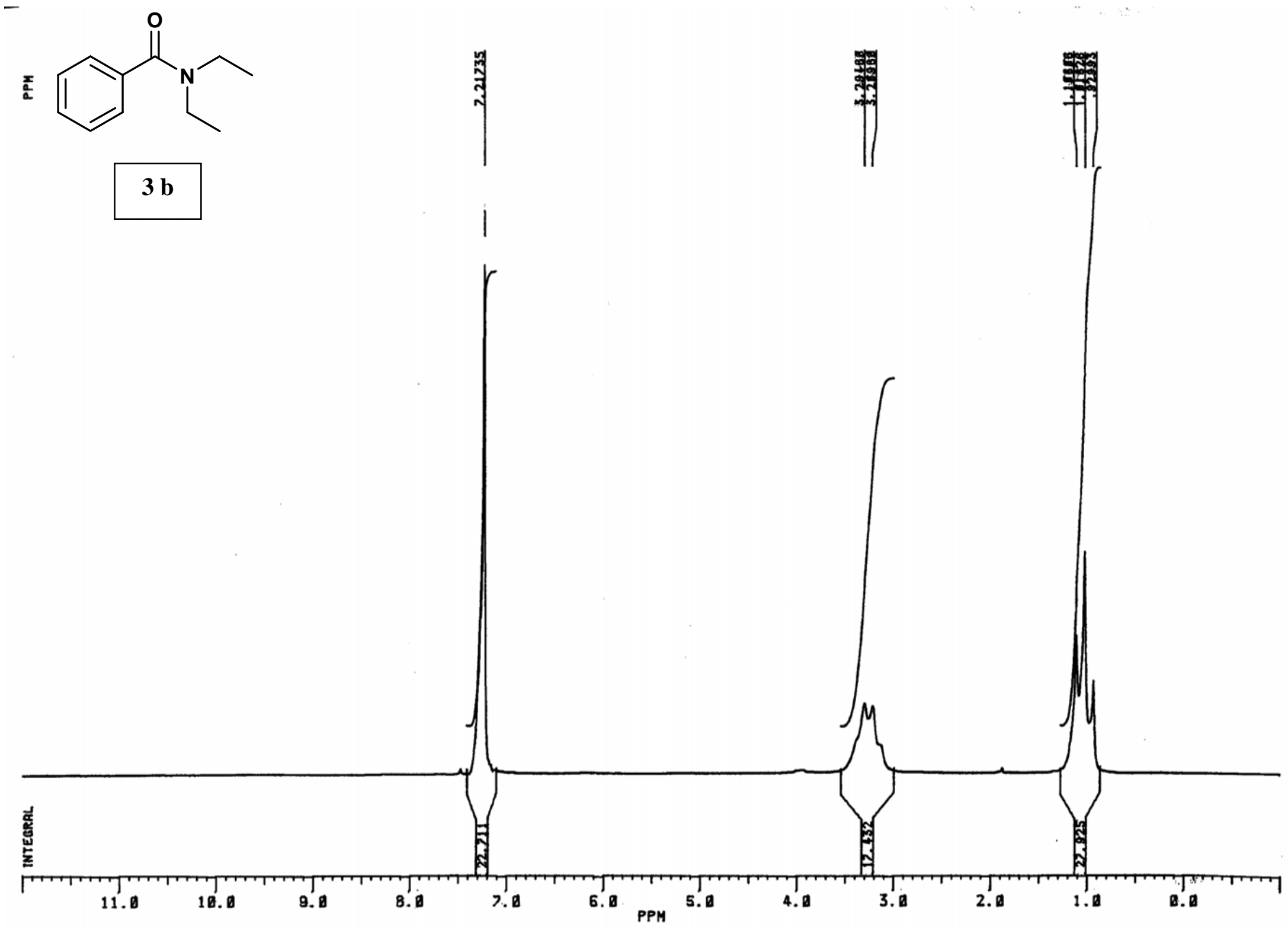

10 


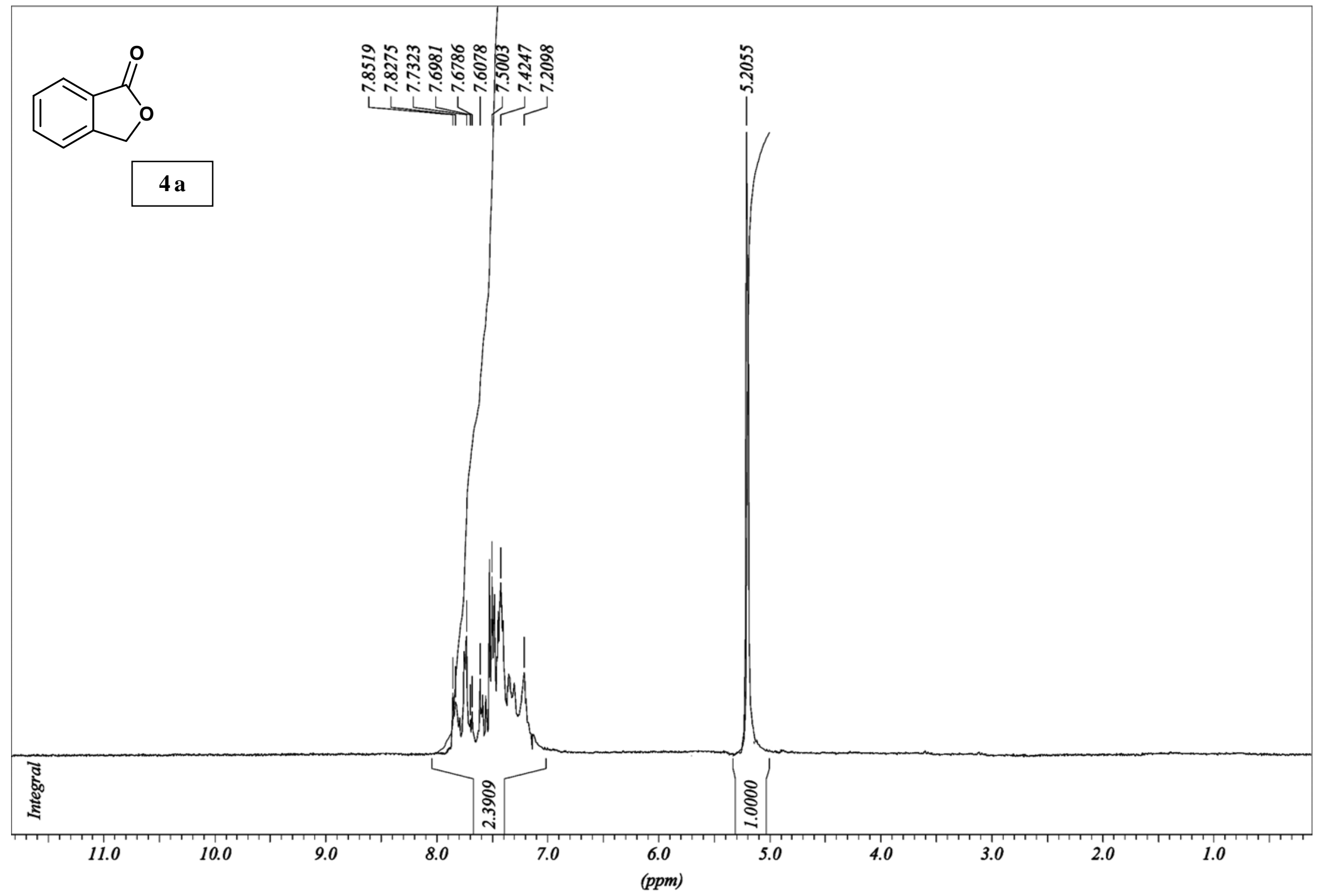




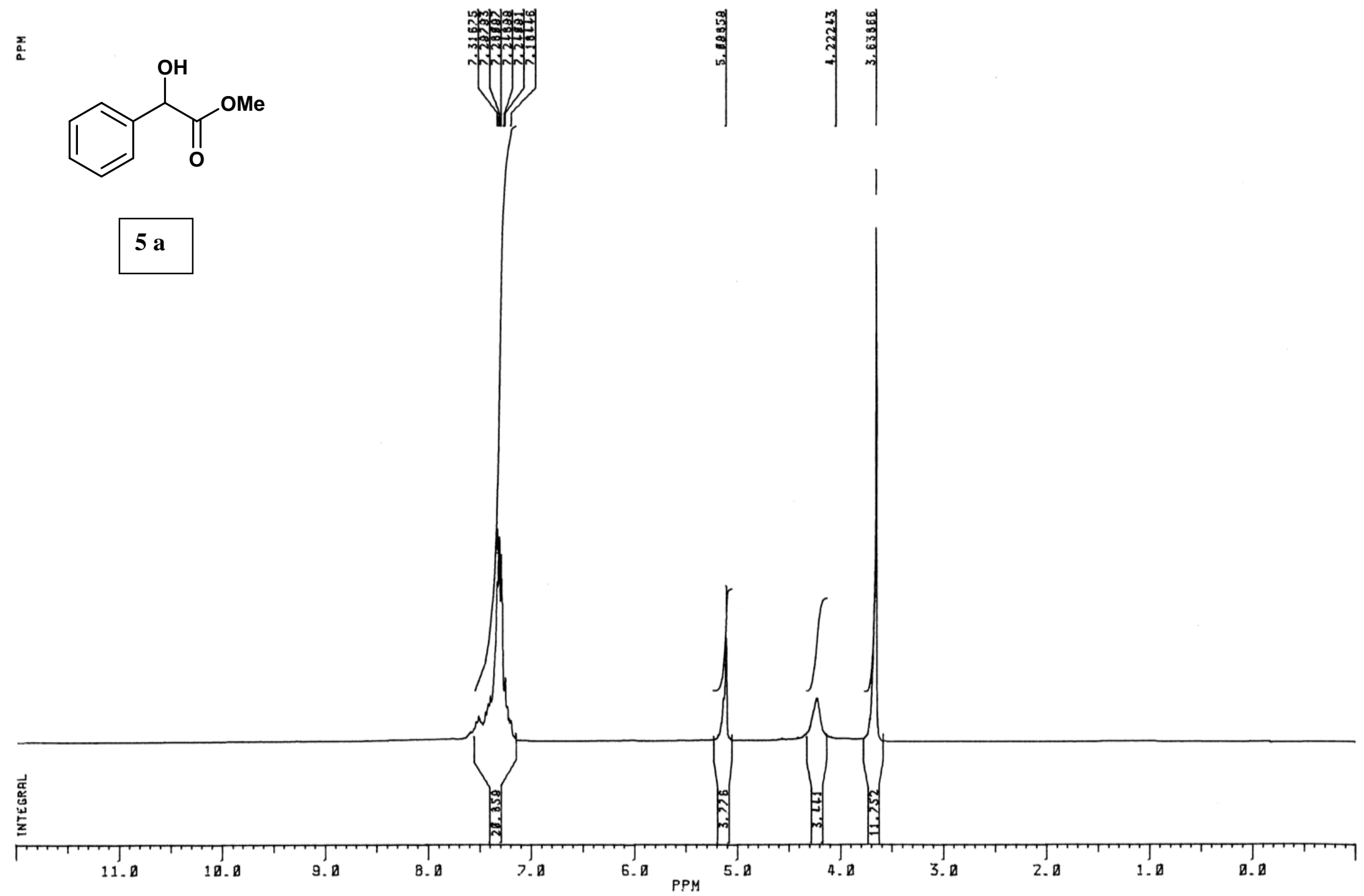

